\title{
The effect of sleep duration in clinical features and impact of migraine: Result from a population-based study
}

\author{
BK Kim* ${ }^{*}, \mathrm{JM} \mathrm{Kim}{ }^{2}, \mathrm{KS} \mathrm{Lee}^{3}, \mathrm{MK} \mathrm{Chu}^{4}$ \\ From The European Headache and Migraine Trust International Congress \\ London, UK. 20-23 September 2012
}

\section{Background}

Although sleep disturbances are a common complaint in migraine patients, the role of sleep habits such sleep duration in clinical features and impact has been poorly analyzed.

\section{Objective}

To assess the influence of sleep duration on clinical features and impact of migraine.

\section{Methods}

We selected a stratified random population sample of Koreans over age 19 and evaluated them with a 60 -item semi-structured interview designed to identify headache type using ICHD-2 criteria and sleep status such as sleep duration and sleep onset time. We also included items for demographics and HIT-6.

\section{Results}

Of 2,836 all participants, 152 were diagnosed as having migraine. The mean sleep duration similar between migraineurs (7.1 \pm 1.5 hours) and non-migraine controls (7.1 \pm 1.3 hours). Among migraineurs, 15 (9.9\%) participants slept ¡ $\hat{A} 5$ hours, 83 (54.6\%) slept 5-7 hours, 44 (28.9\%) slept 7-9 hours, and $10(6.6 \%)$ slept $>9$ hours in weekdays. Migraineurs with sleep duration of $\leq 5$ hours reported higher migraine attack frequency $(9.8 \pm 11.3$ attacks per month) comparing to a sleep duration of $>5$ hours (3.8 \pm 6.3 attacks per month, $\mathrm{p}=0.001)$. Migraineurs with $\leq 5$ hours sleep duration showed a tendency of increased HIT-6 score $(59.7 \pm 9.9)$ comparing to sleep duration of $7-9$ hours $(53.1 \pm 5.8, \mathrm{p}=0.088)$. Unilateral pain was more prevalent among migraineurs with sleep duration of $>5$ hours comparing to sleep duration of $\leq 5$ hours. Headache severity, pulsating quality, aggravation by movement, nausea, vomiting, photophobia and phonophobia was not significant according to sleep duration.

\section{Conclusions}

High attack frequency is associated with sleep duration of $\leq 5$ hours among migraineurs.

\section{Author details}

'Department of Neurology, Eulji University School of Medicine, Korea, Republic of. ${ }^{2}$ Department of Neurology, Chungnam National University, College of Medicine, Korea, Republic of. ${ }^{3}$ Department of Neurology, Seoul St. Mary's Hospital, The Catholic University of Korea, Korea, Republic of. ${ }^{4}$ Department of Neurology, Hallym University College of Medicine, Korea, Republic of

\section{Published: 21 February 2013}

References

1. Rains JC, Poceta JS, Penzien DB: Sleep and headaches. Current Neurology and Neuroscience Report 2008, 8(2):167-75.

2. Rains JC, Poceta JS: Headache and sleep disorders: review and clinical implications for headache management. Headache 2006, 46(9):1344-63.

3. Gilman DK, Palermo TM, Kabbouche MA, Hershey AD, Powers SW: Primary headache and sleep disturbances in adolescents. Headache 2007, 47(8):1189-94

\section{doi:10.1186/1129-2377-14-S1-P6}

Cite this article as: Kim et al:: The effect of sleep duration in clinical features and impact of migraine: Result from a population-based study. The Journal of Headache and Pain 2013 14(Suppl 1):P6. 